date. $\mathrm{HH}$ patients with pain showed significantly lower JSV at MCP 2 and 4 $(p=0.009)$ and exhibited a significantly higher joint asymmetry in MCP $3(p=0.012)$ compared to their pain free colleagues. When looking at clinical correlations we found that time since $\mathrm{HH}$ diagnosis was positively correlated with the MCP4 JSW asymmetry $\left(R^{2}=0.451, p=0.040\right)$ and MCP 4 JSW.SD $\left(R^{2}=0.475, p=0.030\right)$. The number of phlebotomies since diagnosis was strongly correlated with the JSW.SD (MCP2-4: $0.4552<0.581, \mathrm{p}<0.050$ ) at all MCP sites.

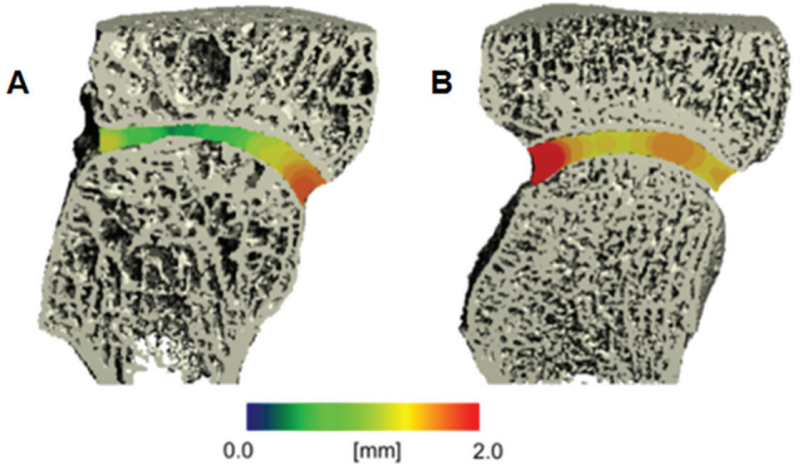

Abstract FRI0596 - Figure 1. 3D surface reconstructions of the MCP3 with the local joint space width mapped into the joint space in psuedo-colour. Blue and green colours reflect narrow joint space width, while red colours code for a broader joint space width. A) 55 year old male with a BMI of $21.9 \mathrm{~kg} / \mathrm{m}^{2}$ who has been diagnosed with hemochromatosis 8 years ago, but received only occasionally phlebotomies. B) 48 year old male (BMI $22.9 \mathrm{~kg} / \mathrm{m}^{2}$ ) with a diagnosis of hemochromatosis of 8 years who received regular phlebotomies every 2 months. Both patients presented at the study date with hand pain. Note the larger and more symmetrical joint space width in patient $B$.

Conclusions: Our study provides the first evidence that joint space assessment of MCPs via HR-pQCT in patients with hereditary hemochromatosis is feasible and can provide a thorough structural joint characterisation and thus support the physician in his initial $\mathrm{HH}$ arthropathy assessment. Our findings suggest, that regular phlebotomies since diagnosis may preserve joint space morphology leading to a more evenly maintained joint space. However, larger studies are needed to validate our results.

Disclosure of Interest: None declared

DOI: 10.1136/annrheumdis-2018-eular.4903

\section{FRI0597 VALIDATION OF WEB-BASED CALIBRATION MODULES FOR IMAGING SCORING SYSTEMS BASED ON PRINCIPLES OF ARTIFICIAL INTELLIGENCE: THE SPARCC MRI SACROILIAC JOINT INFLAMMATION SCORE}

W.P. Maksymowych ${ }^{1,2}$ S. Krabbe ${ }^{3}$, D. Biko ${ }^{4}$, P. Weiss ${ }^{4}$, M.P. Maksymowych ${ }^{5}$, J. Cheah $^{6}$, G. Kröber ${ }^{7}$, U. Weber ${ }^{7}$, K. Danebod ${ }^{7}$, P. Bird ${ }^{8}$, P. Chiowchanwisawakit ${ }^{9}$, J. Moeller ${ }^{10}$, M. Francavilla ${ }^{4}$, J. Stimec ${ }^{11}$, T. Kogay ${ }^{7}$, V. Zubler ${ }^{12}$, M. Battish ${ }^{13}$ N. Winn ${ }^{14}$, D. Rumsey ${ }^{15}$, R. Guglielmi ${ }^{16}$, S.J. Pedersen ${ }^{17}$, H. Boutrup ${ }^{17}$, S. Shafer ${ }^{7}$ J. Jaremko ${ }^{5}$, F. Malik ${ }^{18}$, E. Heffernan ${ }^{19}$, M.P. Johansson ${ }^{17}$, B. Trinh ${ }^{1}$, J. Paschke ${ }^{1}$, R.G. Lambert ${ }^{5} .{ }^{1}$ CaRE Arthritis Ltd; ${ }^{2}$ Medicine, University of Alberta, Edmonton, Canada; ${ }^{3}$ Copenhagen Center for Arthritis Research, Copenhagen, Denmark; ${ }^{4}$ Children's Hospital of Philadelphia, Philadelphia, USA; ${ }^{5}$ Radiology, University of Alberta, Edmonton, Canada; ${ }^{6}$ Hospital for Special Surgery, New York, USA; ${ }^{7}$ Rigshospitalet, Graasten, Denmark; ${ }^{8}$ University of New South Wales, Sydney, Australia; ${ }^{9}$ Mahidol University, Bangkok, Thailand; ${ }^{10}$ Copenhagen University Hospital, Copenhagen, Denmark; ${ }^{11}$ Hospital for Sick Children, Toronto, Canada; ${ }^{12}$ Radiology, Hospital Balgrist, Zurich, Switzerland; ${ }^{13}$ McMaster Children's Hospital, Hamilton, Canada; ${ }^{14}$ The Robert Jones and Agnes Hunt Orthopaedic Hospital, Oswestry, UK; ${ }^{15}$ Pediatrics, University of Alberta, Edmonton, Canada; ${ }^{16}$ Ente Ospedaliero Cantonale, Lugano, Switzerland; ${ }^{17}$ Gentofte hospital, Copenhagen, Denmark; ${ }^{18}$ NYU Center for Musculoskeletal Care, New York, USA; ${ }^{19}$ St. Vincent's University Hospital, Dublin, Ireland

Background: The application and appropriate use of imaging-based scoring instruments is usually based on passive learning from published manuscripts while real-time interaction with instrument developers is often non-feasible. Moreover, most instruments lack knowledge transfer tools that would facilitate attainment of pre-specified performance targets for reader reliability.

Objectives: 1. To develop a web-based calibration module for the SPARCC MRI SIJ Inflammation Score based on consensus scores from these instrument developers, experiential game psychology, and real-time iterative feedback. 2 . To test the feasibility and attainment of pre-specified performance targets for reader reliability.

Methods: The scoring of inflammatory lesions of the SIJ on MRI using the SPARCC method is based on SIJ quadrants and the calibration module is comprised of 50 DICOM cases, each with scans from baseline and 12 weeks after the start of TNF inhibitor therapy. Scans are scored blinded-to-time-point. Continuous visual real-time feedback regarding concordance/discordance of scoring per SIJ quadrant with expert readers is provided by a color-coding scheme. Reliability is additionally assessed by real-time intra-class correlation coefficient with the first ICC data being provided after 20 cases. Accreditation for SPARCC BME score is achieved with status and change score ICC of $>0.8$ and $>0.7$ and is based on the final 20 cases. 26 readers scored the SPARCC BME module ( 7 rheumatology fellows, 2 chiropracters, 1 undergraduate, 8 rheumatologists, 8 radiologists) with 21 having no prior experience. Feasibility was assessed by 8 -item survey.

Results: The majority of readers achieved accreditation for SPARCC BME score on the basis of sufficient reliability with instrument developers for both status and change scores, irrespective of prior experience (table 1). All readers who completed the module a second time, 6 months after the first exposure, achieved accreditation for SPARCC BME score. All readers rated the modules as easy and intuitive with average time for reading each case for SPARCC BME being $8 \mathrm{~min}$.

Abstract FRI0597 - Table 1

\begin{tabular}{|c|c|c|c|c|c|c|}
\hline & \multicolumn{3}{|c|}{ Status Score } & \multicolumn{3}{c|}{ Change Score } \\
\cline { 2 - 7 } & $\begin{array}{c}\text { Mean ICC } \\
(\mathbf{9 5 \% C I )}\end{array}$ & $\begin{array}{c}\text { Median } \\
\text { ICC }\end{array}$ & $\begin{array}{c}\mathbf{N}(\%) \\
\text { Achieving } \\
\text { ICC>0.80* }\end{array}$ & $\begin{array}{c}\text { Mean ICC } \\
(\mathbf{9 5} \% \text { CI) }\end{array}$ & $\begin{array}{c}\text { Media } \\
\mathbf{n} \text { ICC }\end{array}$ & $\begin{array}{c}\mathbf{N}(\%) \\
\text { Achieving } \\
\text { ICC>0.70* }\end{array}$ \\
\hline $\begin{array}{c}\text { All readers } \\
(\mathrm{N}=26)\end{array}$ & $0.84(0.81-0.87)$ & 0.84 & $18(69.2 \%)$ & $0.74(0.69-0.79)$ & 0.76 & $17(65.4 \%)$ \\
\hline $\begin{array}{c}\text { Second read } \\
(\mathrm{N}=8)]\end{array}$ & $0.89(0.87-0.91)$ & 0.89 & $8(100 \%)$ & $0.84(0.79-0.90)$ & 0.86 & $8(100 \%)$ \\
\hline $\begin{array}{c}\text { Naîve readers** } \\
(\mathrm{N}=10)\end{array}$ & $0.83(0.79-0.87)$ & 0.84 & $8(80 \%)$ & $0.74(0.66-0.83)$ & 0.79 & $7(70 \%)$ \\
\hline $\begin{array}{c}\text { Rheumatologists } \\
(\mathrm{N}=8)\end{array}$ & $0.86(0.79-0.92)$ & 0.85 & $6(75 \%)$ & $0.78(0.69-0.87)$ & 0.79 & $6(75 \%)$ \\
\hline $\begin{array}{c}\text { Radiologists } \\
(\mathrm{N}=8)\end{array}$ & $0.84(0.77-0.91)$ & 0.82 & $4(50 \%)$ & $0.70(0.59-0.81)$ & 0.72 & $4(50 \%)$ \\
\hline
\end{tabular}

*Proficiency targets for reader reliability

${ }^{* \star} 7$ rheumatology fellows, 2 chiropractors, 1 undergraduate

Conclusions: Experiential web-based learning is an effective and feasible calibration tool to achieve proficiency targets in the scoring of MRI scans for SIJ inflammatory lesions.

Disclosure of Interest: W. Maksymowych Shareholder of: CaRE Arthritis, S Krabbe: None declared, D. Biko: None declared, P. Weiss: None declared, M. Maksymowych: None declared, J. Cheah: None declared, G. Kröber: None declared, U. Weber: None declared, K. Danebod: None declared, P. Bird: None declared, P. Chiowchanwisawakit: None declared, J. Moeller: None declared, M. Francavilla: None declared, J. Stimec: None declared, T. Kogay: None declared, V. Zubler: None declared, M. Battish: None declared, N. Winn: None declared, D. Rumsey: None declared, R. Guglielmi: None declared, S. Pedersen: None declared, H. Boutrup: None declared, S. Shafer: None declared, J. Jaremko: None declared, F. Malik: None declared, E. Heffernan: None declared, M. Johans son: None declared, B. Trinh: None declared, J. Paschke: None declared, R. Lam bert: None declared

DOI: 10.1136/annrheumdis-2018-eular.6880

\section{FRI0598 \\ THE AGREEMENTS BETWEEN CLINICAL SIGNS AND ULTRASOUND-DETERMINED JOINT INFLAMMATION IN PATIENTS WITH RHEUMATOID ARTHRITIS}

X. Sun, X. Deng, W. Xie, Y. Geng, L. Ji, X. Zhang, Z. Zhang. Department of Rheumatology and Clinical Immunology, Peking University First Hospital, Beijing, China

Background: The identification of synovial inflammation in rheumatoid arthritis (RA) patients mainly depends on the presence of tenderness and/or swelling joints by physical examination, however not entirely reliable. Ultrasound, especially the synovial hyperplasia evaluated by grey scale (GS) and synovitis by power Doppler (PD), is more sensitive in reflecting joint inflammation, but their clinical significance has not been fully understood ${ }^{[1]}$.

Objectives: To investigate the agreement between clinical-detected signs and US features of joint inflammation in wrists and hands, and further determine the grades of GS synovial hyperplasia and PD synovitis which correspond to presence of tenderness or swelling in an individual joint in RA patients.

Methods: Twenty-two joints, including bilateral wrists, proximal interphalangea (PIP) and metacarpophalangeal (MCP) joints, were respectively evaluated by clinical and ultrasound examination by different rheumatologists in 258 RA patients. Ultrasound-determined joint inflammation, including synovitis, tenosynovitis/peritendinitis, were detected, by using semi-quantitative scoring systems (0-3) for GS 
synovial hyperplasia and PD synovitis, and qualitative scoring systems (0/1) for tenosynovitis/peritendinitis.

Results: The median age of 258 enrolled patients were 51.4 years with $82.9 \%$ females. Their median disease duration was 55 months, and median disease activity score based on 28 joint count were 4.6 . In a total of 5676 joints assessed, 968 joints $(17.1 \%)$ were swollen and 1296 joints $(22.8 \%)$ were tender, while on ultrasonography GS synovial hyperplasia was present in 801 (14.1\%) joints, PD synovitis in $476(8.4 \%)$ joints and tenosynovitis/peritendinitis in 108 (1.9\%) joints. The general agreement between clinical signs and ultrasound-determined joint inflammation in all joints was fair $(\kappa=0.365, p<0.01)$. In wrists, joint tenderness showed higher $\kappa$ coefficient $(\kappa=0.329, p<0.01)$ with ultrasound-determined joint inflammation than swelling $(\kappa=0.263, p<0.01)$, while on the contrary, swelling showed higher $\kappa$ coefficient $(\kappa=0.156-0.536, p<0.01)$ with ultrasound-determined joint inflammation than tenderness $(\kappa=0.061-0.355, p<0.05)$ in MCP and PIP joints. Both synovial hyperplasia and synovitis detected by ultrasound had consistently higher agreement with tenderness/swelling than tenosynovitis/peritendinitis. Joint tenderness and swelling had the highest $\kappa$ coefficient with GS $\geq 1$ synovial hyperplasia in most MCP and PIP joints, while with GS $\geq 2$ synovial hyperplasia in wrists. For all 22 joints, $P D \geq 1$ synovitis had the highest $\kappa$ coefficient with clinical tenderness and swelling.
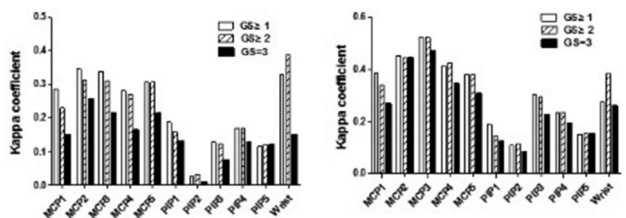

a. $k$ coefficient between tenderness and $G S$ grade
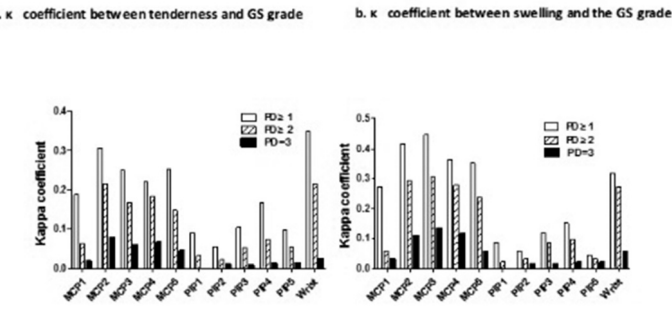

c. $K$ coefficient between tenderness and PD grade d. $K$ coefficient between swelling and the PD grade

Conclusions: Synovitis had better agreement with clinical signs than tenosynovitis/peritendinitis. Joint swelling showed better agreement with these ultrasonographic changes than tenderness for MCP and PIP joints, while the opposite for wrists. The minimal requirements of synovial hyperplasia/synovitis which correspond to clinical signs are GS $\geq 1$ for MCP and PIP joints, GS $\geq 2$ for wrists, but $\mathrm{PD} \geq 1$ for any joint.

\section{REFERENCE:}

[1] Yamada Y, Ogasawara M, Gorai M, et al. The synovial grade corresponding to clinically involved joints and a feasible ultrasound-adjusted simple disease activity index for monitoring rheumatoid arthritis. Mod Rheumatol 2016;26:844-849.

Acknowledgements: We'd like to thank all those who contributed to our study Disclosure of Interest: None declared DOI: 10.1136/annrheumdis-2018-eular.3586

\section{FRI0599 THE RELEVANCE OF THERMOGRAPHY AND NAILFOLD CAPILLAROSCOPY IN OLDER PATIENTS WITH PRIMARY AND SECONDARY RAYNAUD'S PHENOMENON}

S. van Vugt ${ }^{1,2}$, Y. Vreeburg ${ }^{3}$, L. van Vugt ${ }^{2,3}$, G. Schardijn ${ }^{2} .{ }^{1}$ Artis Natura Magistra Zoo; ${ }^{2}$ Specialisten polikliniek Buitenveldert, ${ }^{3} \mathrm{VU}$ medical center, Amsterdam, Netherlands

Background: Raynaud's phenomenon (RP) is defined as episodic attacks of artery and arteriole vasoconstriction. To differentiate between the benign RP (pRP) and the form associated with connective tissue diseases (sRP) the capillary morphology can be studied using nailfold capillaroscopy (nCS). However, abnormal morphology can also be caused due to age-related changes and has been described in patients with diabetes and cardiovascular disease. In addition, this technique cannot provide functional information.

Thermal imaging (thermography; TG) is a non-invasive technique which enables quantification of cutaneous blood vessel function. In veterinary medicine, thermal imaging is applied for various clinical settings. A combined approach using both nCS and TG could improve the differentiation between pRP and sRP.

Objectives: The aim of this pilot study was to determine which technique (TG versus $\mathrm{nCS}$ ) allows the best discrimination amongst older patients with pRP and SRP.

Methods: Thirty patients with RP ( $p R P, n=21 ; s R P, n=9$ ) underwent $n C S$ (Olympus SZ51) and TG (Flirr B 620). Nailfold morphologic features were measured and scored on capillary density, giant capillaries, ramification and hemorrages. The patients were divided into three categories: normal, slightly abnormal (slightly enlarged capillaries) and severely abnormal (destruction of capillary structure and hemorrages).

TG of the hand was performed before, directly after and $10 \mathrm{~min}$ after a cold challenge test with cold manchets of $3^{\circ} \mathrm{C}$. Rewarming and reperfusion were monitored and baseline images and rewarming curves were analysed.

Results: Capillary abnormalities with nCS were found in all patients with SRP (9/ 9) and in 52\% (11/21) of patients with pRP. Out of $11 \mathrm{pRP}$ patients with altered capillary morphology, 7 (63\%) had a cardiovascular disease.

TG demonstrated a lower average temperature at baseline in the pRP group compared to the sRP group $\left(d 1,68^{\circ} \mathrm{C}, p<0,01\right)$. In patients with $\mathrm{pRP}$ temperature decreased after cold induction $\left(-2.34^{\circ} \mathrm{C}, \mathrm{p}=0,01\right)$, whereas in sRP patient temperature stayed consistent $\left(+0.07^{\circ} \mathrm{C}, \mathrm{p}=0,46\right)$ (table 1$)$. In both groups temperature increased ten minutes after cold induction (pRP $+2.62^{\circ} \mathrm{C}, \mathrm{p}<0,01 ; \mathrm{sRP}+1.57^{\circ} \mathrm{C}$, $p<0,01)$.

The gradient of the rewarming curve was significantly lower in patients with sRP compared to the pRP group (median 0.16 vs. $0.26{ }^{\circ} \mathrm{C} / \mathrm{min} ; \mathrm{p}=0.015$ ).

Abstract FRI0599 - Table 1

$\begin{array}{cccc}\begin{array}{c}\text { Average } \\ \text { temperature of } \\ \text { the fingers }\end{array} & \begin{array}{c}\text { Average } \\ \text { temperature of } \\ \text { the fingers just }\end{array} & \begin{array}{c}\text { Average } \\ \text { temperature of the } \\ \text { fingers 10 min after } \\ \text { before the }\end{array} & \begin{array}{c}\text { Average } \\ \text { temperature } \\ \text { recovery }\end{array} \\ \text { immersion in } & \text { immersion test } & \begin{array}{c}\text { removing the hand } \\ \text { from cold water (in }\end{array} & \begin{array}{c}\text { speed (in } \\ { }^{\circ} \mathrm{C} / \mathrm{min} \text { ) }\end{array} \\ \text { cold water (in } & \text { (in }{ }^{\circ} \mathrm{C} \text { ) } & { }^{\circ} \mathrm{C} \text { ) } & \end{array}$

Primary Raynaud Phenomenon 29.4927 .1529 .770 .26 Secondary Raynaud Phenomenon 31.1731 .2432 .810 .16 Capillaroscopy abnormalities 25.8025 .6027 .920 .23 Secondary Raynaud phenomenon and Capillaroscopy abnormalities 27.9928 .1531 .520 .34

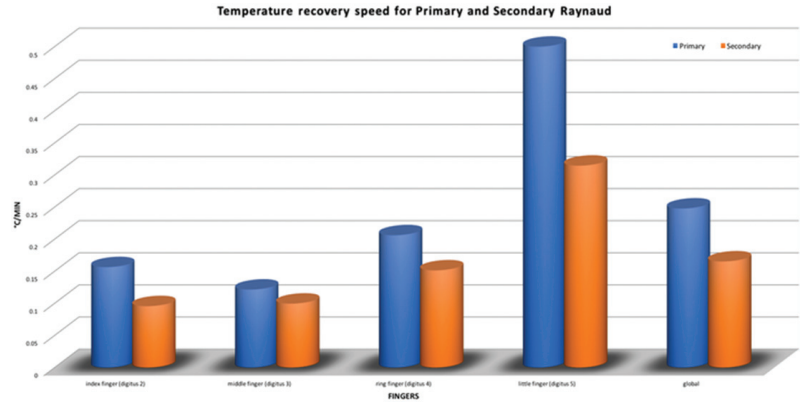

Conclusions: Nailfold capillaroscopy and thermography can reliably be used to measure microvascular damage and dysfunction. TG is better suitable to differentiate between older patients with $\mathrm{pRP}$ and $\mathrm{sRP}$.

Furthermore, in presence of cardiovascular disease, TG appears to be a more reliable technique than nCS for differentiating between patients with $\mathrm{pRP}$ and $\mathrm{SRP}$.

Disclosure of Interest: None declared

DOI: 10.1136/annrheumdis-2018-eular.3351

FRIDAY, 15 JUNE 2018

\section{Public health, health services research and health economics}

\section{FRI0600 \\ METHODS FOR THE ANALYSIS OF ADHERENCE DATA FROM A MEDICATION EVENT MONITORING SYSTEM (MEMS): A SYSTEMATIC REVIEW}

L. Hartman ${ }^{1}$, W. Lems ${ }^{1}$, M. Boers ${ }^{1,2}$. ' Amsterdam Rheumatology and Immunology Center ARC, ${ }^{2}$ Department of Epidemiology and Biostatistics, VU University Medical Center, Amsterdam, Netherlands

Background: Medication adherence can be measured with several methods: medication bottles with an electronic cap are regarded as the gold standard. The cap contains an electronic device which records the date and time of each 